\title{
Prevalence and Antibiotic Susceptibility of Salmonella species Isolated from Beef and its Related Samples in Techiman Municipality of Ghana
}

\author{
Frederick Adzitey*, Joseph Kwame Nsoah, Gabriel Ayum Teye \\ University for Development Studies, Faculty of Agriculture, Animal Science Department,P. O. Box TL 1882, Tamale, Ghana
}

A R T I C L E I N F O

Article history:

Received 01 April 2015

Accepted 23 July 2015

Available online, ISSN: 2148-127X

Keywords:

Antibiotics

Meat

Prevalence

Salmonella species

Ghana

${ }^{*}$ Corresponding Author:

E-mail: adzitey@yahoo.co.uk

\begin{abstract}
A B S T R A C T
Salmonella species are important foodborne pathogens that have been implicated in a number of foodborne outbreaks. A total of 240 beef and its related samples obtained from the Techiman Municipality of Ghana were screened using the conventional method in the Food and Drug Administration-Bacteriological Analytical Manual (FDA-BAM)-USA. The overall prevalence of Salmonella species was $57.08 \%$. The prevalence of Salmonella species ranged from $33.30 \%$ to $75.00 \%$ in the meat and its related samples (table, knife and apron), and $6.30 \%$ to $93.80 \%$ at the various meat sale points (locations where meat is sold). Prevalence of Salmonella species was significantly higher in meat $(75.00 \%)$, table $(60.00 \%)$ and knife $(60.00 \%)$, than apron $(33.33 \%)$. The most contaminated meat sale point was Kenten and Main markets $(93.75 \%)$ and the least contaminated sale point was Sansema junction $(6.25 \%)$. All the Salmonella species were susceptible to ciprofloxacin but resistant to vancomycin. Intermediate resistances occur for all the antibiotics except ciprofloxacin and vancomycin. The Salmonella species also exhibited 23 antibiotic resistant patterns with the pattern EVa (erythromycin and vancomycin) being the commonest (exhibited by nine different isolates). Multiple antibiotic index (MAR index) ranged from 0.11 to 0.67 . This study revealed that beef and its related samples in Techiman markets are contaminated with Salmonella.
\end{abstract}

\section{Introduction}

Salmonella species particularly non-typhoidal Salmonella species is recognized worldwide as an important foodborne pathogen. Scallen et al. (2011) estimated that non-typhoidal Salmonella species is the second largest cause of foodborne illnesses (11\%) after norovirus $(58 \%)$, the leading cause of hospitalizations (35\%) and death $(28 \%)$ in the United States of America. In the European Union, 91,034 human cases of salmonellosis were reported in 2012 (European Food Safety Authority, 2014). Hospitalizations and case fatality were $45.1 \%$ and $0.14 \%$, respectively of confirmed salmonellosis cases (European Food Safety Authority, 2014). Saba et al. (2013) stated that data on salmonellosis is scarce especially in most developing and underdeveloped countries. In countries where data on salmonellosis are available, it is still believed that the magnitude of the incidence is underestimated, as many cases of salmonellosis are not reported (Forshell and Wierup, 2006). Symptoms of salmonellosis in healthy individuals include fever, diarrhoea, nausea, abdominal pain and vomiting (Centers for Disease Control and Prevention, 2013; Miller and Pegues, 2005). In immunecompromised individuals, elderly and children septicaemia, reactive arthritis as well as neurological and neuromuscular illnesses can occur (European Food Safety Authority, 2014; Forshell and Wierup, 2006).
Of all the non-typhoidal Salmonella species, Salmonella Enteritidis and Salmonella Typhimurium are the most frequently reported serovars associated with human foodborne salmonellosis (Department for Environment, Food and Rural Affairs, 2013; European Food Safety Authority, 2014). The common reservoir of non-typhoidal Salmonella species is the gastrointestinal tract of a wide variety of farm animals including poultry, pigs, sheep, goat and cattle (Adzitey et al., 2012a; Department for Environment, Food and Rural Affairs, 2013; European Food Safety Authority, 2014; Frederick and Nurul, 2011). Salmonella species in the gastrointestinal tract of farm animals can end up in meats, meat products and other foodstuffs through cross contamination. Contamination of beef, chevon, mutton, poultry meat, burgers, sausages and many more by Salmonella species has been reported (Adzitey et al., 2010; Adzitey et al., 2011; Adzitey et al., 2014; Bonardi et al., 2013; Department for Environment, Food and Rural Affairs, 2013; European Food Safety Authority, 2014; Kagambèga et al., 2013; Lai et al., 2014; Umeh and Enwuru, 2014). Resistance of foodborne pathogens including non-typhoidal Salmonella species is an increasing public health problem (Adzitey et al., 2012b; European Food Safety Authority, 2004). European Food Safety Authority (2004) reported that the risk to public 
health from the selection of resistant organisms depends on the particular bacterium, the behaviour and prevalence of the bacteria, the antimicrobial in question, the type of resistance, and stage of animal production.

In Ghana, there are fewer reports on the prevalence and antibiotic resistance of Salmonella species in animals and humans. The few studies on Salmonella species have also concentrated much on humans rather than foodborne isolates (Awua-Boateng, 2007; Puopelle, 2014; Saba et al., 2013). However, food including meat and their related samples are important sources of Salmonella species and their association with foodborne infections in Ghana should not be ignored. In a survey by Danikuu (2004) in the Kumasi Municipality of Ghana, 15(6\%) Salmonella species were isolated from various animal species. Adzitey et al. (2011) also isolated Salmonella species from meat samples in the Tamale Municipality of Ghana. Data on the prevalence and antibiotic resistance of Salmonella species in Techiman Municipality is unavailable. Therefore, we report for the first time on the prevalence and antibiotic resistance of Salmonella species in beef and its related samples in Techiman Municipality of Ghana.

\section{Materials and Methods}

\section{Location of Study}

The study was conducted in Techiman Municipality in the Brong Ahafo Region of Ghana. Techiman is located in the Southern part of Ghana and is one of the leading market towns in the south of Ghana (Anonymous, 2014). Techiman Municipality has a population of 104, 212 people and can be located on longitude $07^{\circ} 34^{\prime} 38^{\prime \prime}$ North and latitude $01^{\circ} 55^{\prime} 45^{\prime \prime}$ West (Anonymous, 2014).

\section{Collection of samples}

Two hundred and forty beef and its related samples were collected from various meat sale or processing point(s) in the Techiman Municipality between May 2013 to June 2014. The samples were taken at random from fourteen meat retail shops and one abattoir (the main abattoir in Techiman). Swab samples were collected from beef $(n=60)$, tables $(n=60)$, knives $(n=60)$ and aprons $(n=60)$. The samples were transported under $4^{\circ} \mathrm{C}$ in an ice chest and analyzed immediately on reaching the laboratory.

\section{Isolation and Identification of Salmonella Species}

Isolation and identification of Salmonella species was carried out using a modified method according to the Food and Drug Administration-Bacteriological Analytical Manual (FDA-BAM)-USA (Wallace and Hammack, 2007). Swabs were moistened with sterile distilled water just before swabbing. An area of $10 \mathrm{~cm}^{2}$ of beef, table, knife and apron samples was swabbed. Swabs were preenriched in $10 \mathrm{ml}$ Buffered Peptone Water (BPW) and incubated at $37^{\circ} \mathrm{C}$ for 24 hours. After which $0.1 \mathrm{ml}$ of preenriched aliquots were transferred into $10 \mathrm{ml}$ Rappaport and Vassiliadis (RV) and Selenite Cystine (SC) broths. Samples in RV broths were incubated at $42^{\circ} \mathrm{C}$ for 24 hours while samples in SC broths were incubated at $37^{\circ} \mathrm{C}$ for 24 hours (enrichment). After enrichment $0.1 \mathrm{ml}$ of the aliquots were streaked on Xylose Lysine Deoxycholate
(XLD) and Brilliant Green (BG) agars, and incubated at $37^{\circ} \mathrm{C}$ for $24-48$ hours. Presumptive Salmonella colonies were picked, purified, Gram stained and subjected to the following biochemical tests; growth characteristics on triple sugar iron, lysine iron and Simon citrate agars, and urease production. Salmonella isolates were confirmed by Latex Agglutination Kit for Salmonella (Oxoid Limited, Basingstoke, UK). All media used were also purchased from Oxoid Limited, Basingstoke, UK.

Antimicrobial Susceptibility of Salmonella Species

The disk diffusion method of Bauer-Kirby (1966) was used to determine the antibiotic sensitivity of 45 Salmonella isolates against the following antibiotics; amoxycillin/clavulanic acid (Amc) 30 $\mu \mathrm{g}$; chloramphenicol (C) $30 \mu \mathrm{g}$; gentamicin (Cn) $10 \mu \mathrm{g}$; ceftriaxone (Cro) $30 \mu \mathrm{g}$; ciprofloxacin (Cip) $5 \mu \mathrm{g}$; erythromycin (E) $15 \mu \mathrm{g}$; suphamethoxazole/trimethoprim (Sxt) $22 \mu \mathrm{g}$; tetracycline (Te) $30 \mu \mathrm{g}$ and vancomycin (Va) $30 \mu \mathrm{g}$. The disks were purchased from Oxoid Limited, Basingstoke, UK. Pure cultures of Salmonella were grown overnight in Tryptic Soy Broth (TSB) (Oxoid Limited, Basingstoke, UK) at $37^{\circ} \mathrm{C}$ and the concentration adjusted using sterile TSB until a $0.5 \mathrm{McF}$ arland turbidity was attained. One hundred $\mu l$ of the culture was then swabbed onto Mueller Hinton agar (Oxoid Limited, Basingstoke, UK) using a sterile cotton swab. Three antimicrobial disks were placed on the surface of the agar plate at a distance to avoid overlapping of inhibition zones. The plates were incubated at $37^{\circ} \mathrm{C}$ for 16 to 18 hours and the results were interpreted as sensitive, intermediate, or resistance according to Clinical and Laboratory Standards Institute guidelines (Clinical and Laboratory Standards Institute, 2006). Escherichia coli was used as control in the antimicrobial susceptibility test (Adzitey et al., 2012b).

The multiple antibiotic resistance (MAR) index was calculated and interpreted according to Krumperman (1983) using the formula: $a / b$, where ' $a$ ' represents the number of antibiotics to which a particular isolate was resistant and ' $b$ ' the total number of antibiotics tested.

Statistical Analysis

The data obtained was analysed using generalized linear model of Statistical Package for the Social Sciences (SPSS) Version 17.

\section{Results and Discussion}

Distribution of Salmonella Species in Beef and its Related Samples

The distribution of Salmonella species in beef and its related samples collected from Techiman is shown in Table 1. From Table 1, Salmonella species were isolated from beef (45/60), table (36/60), knife (36/60) and apron (20/60) samples. The prevalence of Salmonella species in apron was significantly lower $(\mathrm{P}<0.05)$ than that of beef, table and knife. Furthermore, beef $(75.00 \%)$ samples were the most contaminated source, followed by table $(60.00 \%)$ and knife $(60.00 \%)$ samples. It is known that the high nutritive value of meat makes it an ideal medium for the growth of bacteria (Prescott et al., 2002). Apron $(33.30 \%)$ samples were the least contaminated source. 
The primary source of Salmonella contamination in this study can be from beef samples. Table surfaces can be contaminated by beef samples placed on them. Knives can be contaminated by beef and table surfaces during cutting. Aprons may have been contaminated by Salmonella species from beef, tables and/or knives. Particles of beef can splash unto aprons during cutting to contaminate them. Also processors might touch table or knife surfaces with their hands and unconsciously use them to rub on their aprons. This study indicates that beef and its related samples in Techiman Municipality of Ghana are contaminated with Salmonella species and consumers are at risk of contracting salmonellosis from consuming beef and/or contact with beef related samples in the Techiman Municipality.

The distribution of Salmonella species in different meat sale points in Techiman Municipality is presented in Table 2. Almost all the samples (15/16) examined at Kenten and Main markets were contaminated by Salmonella species. Most samples collected from slaughter house (14/16), Anyinabrem market (14/16), Site market (13/16), Hansua market (13/16), Brigade market (13/16), Nana Abena market (11/16) and Dwomor market (10/16) were also contaminated by Salmonella species. Isolation of Salmonella species < 7/16 was observed at Takofiannor, Ahenfie, Abanim, and Zongo markets, as well as Zongo-Tamale station and Sansema junction. There were significant differences $(\mathrm{P}<0.05)$ in the prevalence of Salmonella species among the different meat sale points. Positive Salmonella samples from Kenten, Main, Anyinabrem, Site, Hansua, Brigade, Nana Abena and Dwomor markets, and Slaughter house did not differ significantly $(\mathrm{P}>0.05)$ from each other but differed significantly $(\mathrm{P}<0.05)$ from Ahenfie market, Abanim market, Zongo-Tamale station, Zongo market and Sansema junction. Kenten and Main markets were the most contaminated location (93.75\%) while Sansema junction was the least contaminated location $(6.25 \%)$. The findings of this study indicate that all meat sale points in the Techiman Municipality are contaminated by Salmonella species and the prevalence may vary and/or may be similar from location to location.

The differences in the prevalence observed in beef, table, knife and apron samples, and the various meat sale points suggest the level of hygienic practices observed in the handling and processing of meat in Techiman. The standard of hygienic practices in samples and locations with higher prevalence is lower than those samples and locations with lower prevalence. Adzitey et al. (2011) identify Salmonella species in beef sold in selected meat shops at the Tamale Metropolis of Ghana. They attributed the contamination of meat samples to a number of unhygienic practices practiced in the Tamale Metropolis. These practices include using unsterilized knives and equipment, working on dirty tables, selling meat in the open, wearing of dirty cloths and aprons, and busily conversing while selling meat. Contrarily to this study Addo et al. (2007) did not identify Salmonella species in food samples examined in ten selected hotels in Accra, the capital of Ghana. Danikuu (2004) isolated Salmonella species 6\% (15/250) from animals (fowls, pigs and sheep) in the Kumasi Metropolis of Ghana but cattle and goat samples were negative for Salmonella species. Adzitey et al. (2014) also did not identify Salmonella species in beef, apron and table samples examined at the Yendi Municipality of Ghana. Nonetheless they identified Staphylococcus spp., Streptococcus spp., Bacillus spp. Pseudomonas spp., Escherichia coli and Proteus spp. in the beef, apron and table samples (Adzitey et al., 2014).

The prevalence of Salmonella species in cattle or beef samples have been reported in other countries. In Nigeria, Umeh and Enwuru (2014) reported an overall prevalence of Salmonella species in livestock faeces to be $21.80 \%$ while that of cattle was $10.00 \%$. Salmonella species were present $(52 \%)$ in cattle faeces collected from a central abattoir at Ouagadougou, Burkina Faso (Kagambèga et al., 2013). In a study involving cattle in Texas, USA, $19.00 \%$ of feedlot cattle carcasses and $54.00 \%$ of adult cattle carcasses were positive for Salmonella species (Beach et al., 2002). Zhao et al. (2001) examined 210 ground beef samples in retail meats in Washington, DC, USA and found $4(2 \%)$ to be positive for Salmonella species. Measures to reduce the spread of Salmonella species in cattle, beef and it related samples in Techiman and Ghana as a whole will include the practice of biosecurity, feed and water treatment, thermal treatment of carcasses, and the observance of good manufacturing practice (GMP) and hazard analysis critical control point (HACCP).

\section{Antimicrobial Susceptibility}

The antimicrobial susceptibility of 45 Salmonella species were determined against 9 antimicrobial agents, and the results are presented in Table 3.The overall resistance, intermediate and susceptibility was $35.50 \%$ (144/405), 7.90\% (32/405) and 56.54\% (229/405), respectively. All Salmonella species (100\%) examined were resistant to vancomycin but susceptible to ciprofloxacin. A large percentage of the Salmonella species were also resistant to erythromycin $(75.56 \%)$ and susceptible to gentamicin (86.67\%), ceftriaxone (73.33\%), suphamethoxazole/trimethoprim (68.89\%), chloramphenicol (62.22\%), tetracycline (57.78\%) and amoxycillin/clavulanic acid (57.78\%). Intermediate resistances were observed for all the antibiotics except vaconmycin and ciprofloxacin. Intermediate resistance refers to those Salmonella species that were not clearly resistant or susceptible. It has been suggested in clinical diagnoses that patients with intermediate results can be given a higher dosage of antibiotics (Lorian, 2005). Organisms that exhibit intermediate resistance also have the tendency to easily become resistant (Adzitey et al., 2012c). The use of antibiotics in the treatment of diseases and as growth promoters in farm animals, use of antibiotics for treating humans and other factors have been linked to the development of resistant microorganisms including Salmonella species (European Food Safety Authority, 2004; Krumperman, 1983). Resistant Salmonella species can contaminate carcasses, processing equipment, and other foods which pose a risk for public and animal health. 
Table 1 Distribution of Salmonella species in beef, table, knife and apron samples

\begin{tabular}{c|ccc}
\hline Location in Techiman & Number of samples tested & Number of positive samples & \% Prevalence \\
\hline Meat & 60 & 45 & 75.00 \\
Table & 60 & 36 & 60.00 \\
Knife & 60 & 36 & 60.00 \\
Apron & 60 & 20 & 33.30 \\
Overall & 240 & 137 & 57.08 \\
\hline
\end{tabular}

Table 2 Distribution of Salmonella species in different meat sale points in Techiman

\begin{tabular}{l|ccc}
\hline \multicolumn{1}{c|}{ Location in Techiman } & Number of samples tested & Number of positive samples & \% Prevalence \\
\hline Kenten market & 16 & 15 & 93.75 \\
Main market & 16 & 15 & 93.75 \\
Slaughter house & 16 & 14 & 87.50 \\
Anyinabrem market & 16 & 14 & 87.50 \\
Site market & 16 & 13 & 81.25 \\
Hansua market & 16 & 13 & 81.25 \\
Brigade market & 16 & 13 & 81.25 \\
Nana Abena market & 16 & 11 & 68.75 \\
Dwomor market & 16 & 10 & 62.50 \\
Takofiannor market & 16 & 6 & 37.50 \\
Ahenfie market & 16 & 4 & 25.00 \\
Abanim market & 16 & 3 & 18.75 \\
Zongo-Tamale station & 16 & 3 & 18.75 \\
Zongo market & 16 & 2 & 12.50 \\
Sansema junction & 16 & 1 & 6.25 \\
Overall & 240 & 137 & 57.08 \\
\hline
\end{tabular}

Table 3 Percentage antibiotic resistance of Salmonella species isolated from meats and it related samples

\begin{tabular}{|c|c|c|c|c|}
\hline \multirow{2}{*}{ Antimicrobial } & \multicolumn{4}{|c|}{ Salmonella species } \\
\hline & $* \mathrm{n} / 45$ & $\mathrm{R}(\%)$ & $\mathrm{I}(\%)$ & $\mathrm{S}(\%)$ \\
\hline Amoxycillin/clavulanic acid (Amc) 30 $\mu \mathrm{g}$ & 13.00 & 28.89 & 13.33 & 57.78 \\
\hline Chloramphenicol (C) $30 \mu \mathrm{g}$ & 11.00 & 24.44 & 13.33 & 62.22 \\
\hline Ciprofloxacin (Cip) $5 \mu \mathrm{g}$ & 0.00 & 0.00 & 0.00 & 100.00 \\
\hline Ceftriaxone (Cro) $30 \mu \mathrm{g}$ & 8.00 & 17.78 & 8.89 & 73.33 \\
\hline Gentamicin (Cn) $10 \mu \mathrm{g}$ & 3.00 & 6.67 & 6.67 & 86.67 \\
\hline Erythromycin (E) $15 \mu \mathrm{g}$ & 34.00 & 75.56 & 22.22 & 2.22 \\
\hline Suphamethoxazole/trimethoprim (Sxt) $22 \mu \mathrm{g}$ & 12.00 & 26.67 & 4.44 & 68.89 \\
\hline Tetracycline (Te) $30 \mu \mathrm{g}$ & 18.00 & 40.00 & 2.22 & 57.78 \\
\hline Vancomycin (Va) $30 \mu \mathrm{g}$ & 45.00 & 100.00 & 0.00 & 0.00 \\
\hline
\end{tabular}

*n, number of resistant Salmonella species; $\mathrm{S}$, susceptible; I, Intermediate; R, resistant

Table 4 shows the antibiotic resistance profile and Multiple Antibiotic Resistance (MAR) index of individual Salmonella species from different sources. The Salmonella species exhibited 23 antibiotic resistant patterns with MAR index ranging from 0.11 to 0.67 . The majority of the Salmonella species (14 isolates) were resistant to three antibiotics (MAR index of 0.33), followed by resistant to two antibiotics (12 isolates; MAR index of 0.22), resistant to four (6 isolates; MAR index of 0.44 ) and five antibiotics (6 isolates; MAR index of 0.56), resistant to one antibiotic (4 isolates; MAR index of 0.11) and resistant to six antibiotics (3 isolates; MAR index of 0.67). The resistant pattern EVa was the commonest and was exhibited by 9 different Salmonella isolates. The 3 Salmonella isolates that were resistant to 6 different antibiotics exhibited the resistant patterns AmcCESxtTeVa (2 isolates) and CCnESxtTeVa (1 isolate). Of the 6 Salmonella isolates that were resistant to five different antibiotics, 2 each exhibited the pattern AmcCETeVa and CESxtTeVa and 1 each exhibited the pattern CCroESxtVa and CnESxtTeVa.

Saba et al. (2013) analysed four Salmonella species isolated from humans in the Tamale Metropolis and found that they were all susceptible to amoxicillin-clavulanate, ciprofloxacin, gentamicin, tetracycline and chloramphenicol. In this study we found $100.00 \%$ susceptibility to ciprofloxacin but high resistance to gentamicin. We also found some resistances to amoxicillin-clavulanate, chloramphenicol and tetracycline. Puopelle (2014) isolated Salmonella species from humans in Akwatia, Eastern Region of Ghana and reported a resistant of $76.30 \%$ to trimethoprim/sulfamethoxaxole. All the Salmonella species $100.00 \%$ were susceptible to ciprofloxacin and 
norfloxacin (Puopelle, 2014). Our findings on the susceptibity to trimethoprim/sulfamethoxaxole and ciprofloxacin were similar to that of Puopelle (2014) but differ in terms of norfloxacin. Danikuu (2014) reported that multidrug resistance was a common feature in Salmonella species isolated from livestock in the Kumasi
Metropolis. All the isolates were resistant to tetracycline but susceptible to ciprofloxacin (Danikuu, 2014). The results obtained for ciprofloxacin was in agreement with this current work but not the result for tetracycline. We found some resistance $(40 \%)$, intermediate resistance $(2.22 \%)$ and susceptibility to tetracycline $(57.78 \%)$.

Table 4 Antibiotic resistance profile and multiple antibiotic resistance index of individual Salmonella species from different sources

\begin{tabular}{|c|c|c|c|c|c|}
\hline Serial Number & Salmonella code & Source & Antibiotic resistant profile $^{\mathrm{a}}$ & Number of antibiotics & MAR index \\
\hline 1 & NAT3 & Table & AmcCESxtTeVa & 6 & 0.67 \\
\hline 2 & TMT4 & Table & AmcCESxtTeVa & 6 & 0.67 \\
\hline 3 & DMM4 & Meat & AmcCETeVa & 5 & 0.56 \\
\hline 4 & DMK2 & Knife & AmcCETeVa & 5 & 0.56 \\
\hline 5 & STT2 & Table & AmcCnETeVa & 4 & 0.44 \\
\hline 6 & ZK3* & Knife & AmcCroVa & 3 & 0.33 \\
\hline 7 & SKK4 & Knife & AmcCSxtVa & 4 & 0.44 \\
\hline 8 & NAM4 & Meat & AmcETeVa & 4 & 0.44 \\
\hline 9 & ABM1 & Meat & AmcETeVa & 4 & 0.44 \\
\hline 10 & NAK3 & Knife & AmcEVa & 3 & 0.33 \\
\hline 11 & STM3 & Meat & AmcEVa & 3 & 0.33 \\
\hline 12 & AYK4 & Knife & AmcEVa & 3 & 0.33 \\
\hline 13 & $\mathrm{ABM} 3$ & Meat & AmcTeVa & 3 & 0.33 \\
\hline 14 & SHM1 & Meat & CCnESxtTeVa & 6 & 0.67 \\
\hline 15 & HST3 & Table & CCroESxtVa & 5 & 0.56 \\
\hline 16 & TMM2 & Meat & CESxtTeVa & 5 & 0.56 \\
\hline 17 & STK2 & Knife & CESxtTeVa & 5 & 0.56 \\
\hline 18 & TMK3 & Knife & CETeVa & 4 & 0.44 \\
\hline 19 & HSM2 & Meat & CETeVa & 3 & 0.33 \\
\hline 20 & SHT1 & Table & CnESxtTeVa & 5 & 0.56 \\
\hline 21 & TSMI & Meat & CroEVa & 3 & 0.33 \\
\hline 22 & TSM2 & Meat & CroEVa & 3 & 0.33 \\
\hline 23 & ZK3 & Knife & CroEVa & 3 & 0.33 \\
\hline 24 & SM4 & Meat & CroSxtVa & 3 & 0.33 \\
\hline 25 & TSTI & Table & CroVa & 2 & 0.22 \\
\hline 26 & NAK1 & Knife & CroVa & 2 & 0.22 \\
\hline 27 & BGK4 & Knife & ESxtTeVa & 4 & 0.44 \\
\hline 28 & BGM2 & Meat & ESxtVa & 3 & 0.33 \\
\hline 29 & BGT2 & Table & ESxtVa & 3 & 0.33 \\
\hline 30 & STK3 & Knife & ETeVa & 3 & 0.33 \\
\hline 31 & BGT3 & Table & ETeVa & 3 & 0.33 \\
\hline 32 & ZM4 & Meat & $\mathrm{EVa}$ & 2 & 0.22 \\
\hline 33 & ZM4* & Meat & $\mathrm{EVa}$ & 2 & 0.22 \\
\hline 34 & TSTI* & Table & $\mathrm{EVa}$ & 2 & 0.22 \\
\hline 35 & NAT4 & Table & EVa & 2 & 0.22 \\
\hline 36 & ABM4 & Meat & $\mathrm{EVa}$ & 2 & 0.22 \\
\hline 37 & BGT3 & Table & $\mathrm{EVa}$ & 2 & 0.22 \\
\hline 38 & AYTI & Table & $\mathrm{EVa}$ & 2 & 0.22 \\
\hline 39 & AYM1 & Meat & $\mathrm{EVa}$ & 2 & 0.22 \\
\hline 40 & BGT2 & Table & $\mathrm{EVa}$ & 2 & 0.22 \\
\hline 41 & HSK1 & Knife & $\mathrm{TeVa}$ & 2 & 0.22 \\
\hline 42 & AFM4 & Meat & $\mathrm{Va}$ & 1 & 0.11 \\
\hline 43 & DMT2 & Table & $\mathrm{Va}$ & 1 & 0.11 \\
\hline 44 & SHM4 & Meat & $\mathrm{Va}$ & 1 & 0.11 \\
\hline 45 & BGK1 & Knife & $\mathrm{Va}$ & 1 & 0.11 \\
\hline
\end{tabular}

${ }^{a}$ Amoxycillin/clavulanic acid (Amc) $30 \mu \mathrm{g}$; Chloramphenicol (C) $30 \mu \mathrm{g}$; Ciprofloxacin (Cip) $5 \mu \mathrm{g}$; Ceftriaxone (Cro) $30 \mu \mathrm{g}$; Gentamicin (Cn) $10 \mu \mathrm{g}$; Erythromycin (E) $15 \mu \mathrm{g}$; Suphamethoxazole/Trimethoprim (Sxt) $22 \mu \mathrm{g}$; Tetracycline (Te) $30 \mu \mathrm{g}$; Vancomycin (Va) $30 \mu \mathrm{g}$. 
In other countries such as Nigeria, Umeh and Enwuru (2014) reported that Salmonella species isolated from some farm animals showed resistance profile ranging from 1-9 antimicrobials. Resistance to tetracycline and gentamycin was $81.00 \%$ and $14.00 \%$, respectively (Umeh and Enwuru, 2014). In Burkina Faso, Kagambèga et al. (2013) reported that $52(14 \%)$ of 383 Salmonella isolates were resistant to one or more antimicrobials tested, and 23 of these were from cattle, 23 from poultry and 6 from hedgehog faeces. Sixty four percent (64\%) showed decreased sensitivity (intermediate resistance) to one or more antimicrobial (Kagambèga et al., 2013). In Italy, Bonardi et al. (2013) reported that all Salmonella species isolated from pigs at slaughter were susceptible to ciprofloxacin and gentamicin, and $56 \%$ were resistant to tetracycline. In food producing animals in China, the resistant rate for ciprofloxacin was $41.5 \%$ and more than $99 \%$ of the Salmonella isolates collected were resistant to at least one antibiotic (Lai et al., 2014). Lai et al. (2014) also reported that Salmonella resistance rates for 15 antibiotics in 2012 were significantly higher than those in 2009. Resistance to tetracycline seems to be common in Salmonella strains from food animals in the European Union in 2002 (European Food Safety Authority, 2004).

The antibiotic resistances reported in this study were either similar or differ from studies by other authors in Ghana and other countries. Differences in resistant rate have been attributed to differences in samples examined, sampling procedure, breakpoints used and the level of usage of antibiotics in animal farming and human therapeutic purposes (European Food Safety Authority, 2004; Forshell and Wierup, 2006). Bring to after attributed Antibiotics are not normally used to treat people with Salmonella infection because the infection is self-limiting in 5-7 days (Centers for Disease Control and Prevention, 2013). However, in situations where antibiotics are required a variety of antibiotics such as sulfonamides (trimethoprim/sulfamethoxazole), penicillins (amoxicillin), cephalosporins (ceftriaxone) and flouroquinolones (ciprofloxacin) have been suggested (Centers for Disease Control and Prevention, 2013; Miller and Pegues, 2005). In this study all the Salmonella species were susceptible to ciprofloxacin. Studies conducted in Ghana by Danikuu (2014), Puopelle (2014) and Saba et al. (2013) also indicated that all Salmonella species isolated were susceptible to ciprofloxacin. Therefore ciprofloxacin (flouroquinolones) can be the first antibiotic of choice for treating Salmonellosis in Ghana and especially when the infection is caused by the consumption of beef in the Techiman Municipality. In the absence of ciprofloxacin, gentamicin may be used before ceftriaxone, suphamethoxazole/trimethoprim and amoxycillin/clavulanic acid.

In conclusion, the overall prevalence of Salmonella species was $57.08 \%$. The prevalence in meat and it related samples ranged from $33.30 \%$ to $75.00 \%$ while the prevalence among the various meat sale points ranged from $6.25 \%$ to $93.75 \%$. There is the need for meat handlers, processors and sellers in Techiman and Ghana as a whole to observe hygienic practices in the handling, processing and selling of meats and meat products. Salmonella species isolated from beef and it related samples exhibited varying resistances to antibiotics. Averagely, $56.54 \%$ were susceptible, $7.90 \%$ were intermediate and $35.50 \%$ were resistant. Total susceptibility and resistance occurred for ciprofloxacin and norfloxacin respectively. Multiple antibiotic index ranged from 0.11 to 0.67 (that is resistant to 1 to 6 different antibiotics). Majority of the Salmonella species were resistant to three antibiotics but the resistant pattern, EVa was the commonest. There is the need to control the use of antibiotics in animal farming and treatment of humans in Ghana to curb the incidence of increasing multidrug resistant Salmonella species. The findings of this study can serve as baseline information on the prevalence and antibiotic resistance of Salmonella species from meat samples in Ghana to monitor trends in the future.

\section{References}

Addo KK, Mensah GI, Bonsu C, Akyeh ML. 2007. Food and its preparation conditions in hotels in Accra, Ghana: a concern for food safety. African Journal of Food Agriculture Nutrition and Development 7( 5): 1-12.

Adzitey F, Abdul-Aziz A, Moses O. 2014. Microbial quality of beef in the Yendi Municipality of Ghana. Global Journal of Animal Scientific Research 2: 10-17.

Adzitey F, Huda N, Ali GRR. 2012a. Prevalence and antibiotic resistance of Campylobacter, Salmonella, and $L$. monocytogenes in ducks-a review. Foodborne Pathogen and Diseases 9: 498-505.

Adzitey F, Rusul G, Huda N. 2012b. Prevalence and antibiotic resistance of Salmonella serovars in ducks, duck rearing and processing environments in Penang, Malaysia. Food Research International 45: 947-952.

Adzitey F, Rusul G, Huda N, Cogan T, Corry J. 2012c. Prevalence, antibiotic resistance and RAPD typing of Campylobacter species isolated from ducks, duck rearing and processing environments in Penang, Malaysia. International Journal of Food Microbiology 154: 197-205.

Adzitey F, Teye GA, Kutah WN, Adday S. 2011. Microbial quality of beef sold on selected markets in the Tamale Metropolis in the Northern Region of Ghana. Livestock Research for Rural Development 23: 5 .

Adzitey F, Teye GA, Ayim AG, Adday S. 2010. Microbial quality of chevon and mutton sold in Tamale Metropolis of Northern Ghana. Journal of Applied Sciences and Environmental Management 14: 53-55.

Anonymous. 2014. Techiman. Available at: http://en.wikipedia.org/ wiki/Techiman [Accessed 25 December, 2014].

Awua-Boateng NA. 2007. Incidence of Salmonella bacteraemia and antibiotic resistance of Salmonella in paediatric patients in Kumasi. A Master's Thesis submitted to the Department of Clinical Microbiology, Kwame Nkrumah University of Science and Technology, Ghana.

Beach JC, Murano EA, Acuff GR. 2002. Prevalence of Salmonella and Campylobacter in beef cattle from transport to slaughter. Journal of Food Protection 65: 1687-1693.

Bauer AW, Kirby WMM, Sherris JC, Turk M. 1966. Antibiotic susceptibility testing by a standardized single disc method. American Journal of Clinical Pathology 45: 493-496.

Bonardi S, Bassi L, Brindani F, D'Incau M, Barco L, Carra E, Pongolinie S. 2013. Prevalence, characterization and antimicrobial susceptibility of Salmonella enterica and Yersinia enterocolitica in pigs at slaughter in Italy. International Journal of Food Microbiology 163: 248-257. 
Centers for Disease Control and Prevention, 2013. Salmonella: Diagnosis and Treatment. Available at: http://www.cdc.gov/ salmonella/general/diagnosis.html [Accessed 15 December, 2014].

Clinical and Laboratory Standards Institute, 2006. Methods for antimicrobial dilution and disk susceptibility testing of infrequently isolated or fastidious bacteria; Approved Guideline (M45-A). Clinical and Laboratory Standards Institute, Wayne, PA.

Department for Environment, Food and Rural Affairs, 2013. Zoonoses report UK. Available at: https://www.gov.uk/government/uploads/system/uploads /attachment_data/file/ 236983/pb13987-zoonoses-report2012.pdf. [Accessed 15 December, 2014].

Danikuu MF. 2004. Isolation and serotyping of Salmonella from slaughtered food animals in the Kumasi Metropolis. Available at: http://ir.knust.edu.gh/handle/123456789/1936 [Accessed 25 December, 2014].

European Food Safety Authority, 2014. The European Union Summary Report on Trends and Sources of Zoonoses, Zoonotic Agents and Food-borne Outbreaks in 2012. European Food Safety Authority Journal 12(2): 1-312.

European Food Safety Authority, 2004. The use of antimicrobials for the control of Salmonella in poultry. European Food Safety Authority Journal 115: 1-76,

Frederick A, Huda N. 2011. Salmonellas, poultry house environments and feeds: a review. Journal of Animal and Veterinary Advances 10: 679-685.

Forshell LP, Wierup M. 2006. Salmonella contamination: a significant challenge to the global marketing of animal food products. Revue Scientifique et Technique - Office International Des Epizooties 25: 541-554.

Kagambèga A, Lienemann T, Aulu L, Traoré AS, Barro N, Siitonen A, Haukka K. 2013. Prevalence and characterization of Salmonella enterica from the faeces of cattle, poultry, swine and hedgehogs in Burkina Faso and their comparison to human Salmonella isolates. BMC Microbiology 13:253.

Krumperman PH, 1983. Multiple antibiotic resistance indexing of Escherichia coli to identify high-risk sources of fecal contamination of food. Applied and Environmental Microbiology 46: 165-170.
Lai J, Wu C, Wu C, Qi J, Wang Y, Wang H, Liu Y, Shen J. 2014. Serotype distribution and antibiotic resistance of Salmonella in food-producing animals in Shandong province of China, 2009 and 2012. International Journal of Food Microbiology 180: 3038.

Lorian V. 2005. Antibiotics in laboratory medicine, $5^{\text {th }}$ ed. Lippincott Williams \& Wilkins, Philadelphia, PA.

Miller S, Pegues D 2005. Salmonella Species, including Salmonella Typhi, in Mandell, Douglas and Bennett's. Principles and Practice of Infectious Diseases, $6^{\text {th }}$ ed. 220, 2636-2650.

Prescott LM, Harley JP, Klein DA. 2002. Food and industrial microbiology. Mc Graw- Hill Companies, Inc., New York, USA. 125-964.

Puopelle DM. 2014. Prevalence of Salmonella infections in patients attending St. Dominic Hospital, (Akwatia)-Eastern Region. A Master's Thesis submitted to the Department of Clinical Microbiology, Kwame Nkrumah University of Science and Technology, Ghana.

Saba CK, Escudero JA, Herrera-Leon S, Porrero MC, Suarez M, Dominguez L, Demuyakor, B, Gonzalez-Zorn B. 2013. First identification of Salmonella Urbana and Salmonella Ouakam in humans in Africa. The Journal of Infection in Developing Countries 7: 691-695.

Scallan E, Hoekstra RM, Angulo FJ, Tauxe RV, Widdowson MA, Roy SL, Jones JL, Griffin, PM. 2011. Foodborne illness acquired in the United States-major pathogens. Emerging Infectious Diseases 17: 7-15.

Umeh S, Enwuru CP. 2014. Antimicrobial resistance profile of Salmonella isolates from livestock. Open Journal of Medical Microbiology 4: 242-248.

Wallace HA, Hammack TSI. 2007. Salmonella in Bacteriological Analytical Manual, http://www.fda.gov/Food/ScienceResearch/ LaboratoryMethods/BacteriologicalAnalyticalManualBAM/UC M070149 [Accessed 2 January 2013].

Zhao C, Ge B, De Villena J, Sudler R, Yeh E, Zhao S, White DG, Wagner D, Meng J. 2001. Prevalence of Campylobacter spp., Escherichia coli, and Salmonella serovars in retail chicken, turkey, pork, and beef from the greater Washington, D.C., area. Applied and Environmental Microbiology 67: 5431-5436. 